\title{
Aesthetic Otoplasty, Reduction of Shell, Neo-antihelix- plasty, Ear Shell Mastoid Reangulation Procedures
}

\author{
Paoliello V, Carlo Paoliello G \\ Rua Alberto De Oliveira Santos, Brazil
}

\begin{abstract}
This study aims to demonstrate the technical approach for the correction of antihelix flattening (Kaye's Method), for shell reduction by wedge resection and for skull reangulation.(Frank Welsh).
\end{abstract}

Keywords: Otoplasty, Resection of the shell, Neo antihelixplasty.

\section{Purpose}

The surgical correction of protruding ears is intended to correct the partial deletion or total agenesis of the anti helix, the widening of the shell when it's present to an abnormal degree, and skull ear angle that is increased in between 45 and 60 degrees (less is desirable).

\section{Operative Approach}

First, we deliniate, in the mastoid ear notch a zone to be resected in the desired shape, from the upper pole to near the lobe (Figure 2). Resection of the shell can go from the antihelix to the entry of theexternal ear canal, including it all, until there is total or partial loss of cartilage surface tension, whichcan be checked simply by applying pressure with the finger in the ear (in the middle anterior face of the ear). We deliniate the new anti-helix to the desired width and length (Figure 6). A tunnel under the perichondriun is made through the back of the ear on the tail of the antihelice. The tunneling can be done with Freer periosteumrhinoplasty detacher or appropriate rasps (Figure A). Multiple vertical incisions should be made in this cartilage with a nasal septum scalpel or common scalpel. Bear in mind that only the cartilage is to be incised, preserving the perichondrium. The appropriate amount of antihelix roll is then maintained in the ear that undergone abrasion, shaving or stripping of the cartilage in order to soften it, by reducing the surface tension,to allow it to fold over itself.This is done by several regular sutures that enter through point shaped incisions along the crest of the shell on the front of the ear. (Figure B and C). These stiches should be made with colorless monofilament nylon 4.0 or 5.0. This approach for the formation of neo antihelix may be done separately or combined with the reduction of the shell, if needed. Some authors prefer abrasion straightforward, in order to obtain the desired results. correction and shell floor ear reangulation Fusiform resection of skin and subcutaneous tissue in an area previously marked retro auricular (Figure 2). Resection of the perichondrium and cartilage, by incising transfixing demarcation with straight needles and methylene blue points in the cartilage of the shell,can be made as a guide for the incision (Figure 3) make a fusiform incision on a line joining these points, dryingthe cartilage completely. Adjustment of the edges of the remaining areas, can be done with scissors.Anchoring the free top edge of the Shell to the mastoid aponeurosis with as many stitches as needed (Three or four) with monofilament nylon 3.0. Finally suture on skin in the retro auricular groove with running monofilament nylon 5.0 or simply intradermal monocryl 4.0 running suture (Figure 4). Repeat this technique until we have the ideal positioning of the ear at the desired angle thus avoiding the"telephone"defomity.

\section{Results and Conclusions}

With this method, we can get an ideal position of the ear next to the head. The final look is natural, with the final suture positioned

\begin{tabular}{|l|l|}
\hline Quick Response Code: & *Corresponding author: Victor Paoliello, RuaCaramuru 104, Vitória ES 29015020, Brazil \\
Received: 15 May, 2021 & Published: 16 June, 2021 \\
& Citation: Paoliello V, Carlo PG. Aesthetic Otoplasty, Reduction of Shell, Neo-antihelixplas- \\
ty, Ear Shell Mastoid Reangulation Procedures. Mod Res Plast Recon Sur. 2021;1(2):1-8. DOI: & $10.53902 /$ MRPRS.2021.01.000508 \\
\hline
\end{tabular}


in the retro auricular groove. A remaining vertical wrinkle on the anterior surface of the shell may be present, but, with time, it reduces and becomes acceptable. We have no recurrence of the cases we operated on. The objective of neo antihelix is to promoteflattening correction of the antihelix and protruding ear at the top. The use of headbands is recommended for a period of 30 days at home and especially while sleeping.

Diffenbach (1845)- Promoted only skin excision.

Ely (1881) - Excision of the skin and of the shell.

Luckett (1910) - Created a fold of antihelix by excision of a cartilage layer

Mustarde(1963) - Suggested isolated sutures in antihelix

Furnas (1968) - Emphasized the removal of soft tissue and suture shell-mastoid

Frank Welsh (1979) Standardized and simplified the treatment of shellmegalia by wide resection. Easier to match asymmetries and better placement in the retroauricularis sulcus with no recurrence of protruding ears. ${ }^{1-5}$

\section{Acknowledgments}

None.

\section{Funding}

None.

\section{Conflicts of Interest}

Author declares that there is no conflict of interest.

\section{References}

1. Welsh F. Otoplasty with excision of conchal floor. Transactions of the Seventh International Congress of Plastic. Reconstructive Surgery Rio de Janeiro Brazil. 1979.

2. Kaye BL. A simplified Method for correcting the Prominent ears. Plast Reconstruct Surgery. 1967;40(1):44-48.

3. Frank H Netter. $2^{\text {nd }} e d ; 2001$.

4. Paoliello Victor. Types of skin suture in Plastic Surgery. JBM. 68(4):103108.

5. Pitanguy Ivo. Body Contouring Surgery. Prominent ears. p. 306-314.

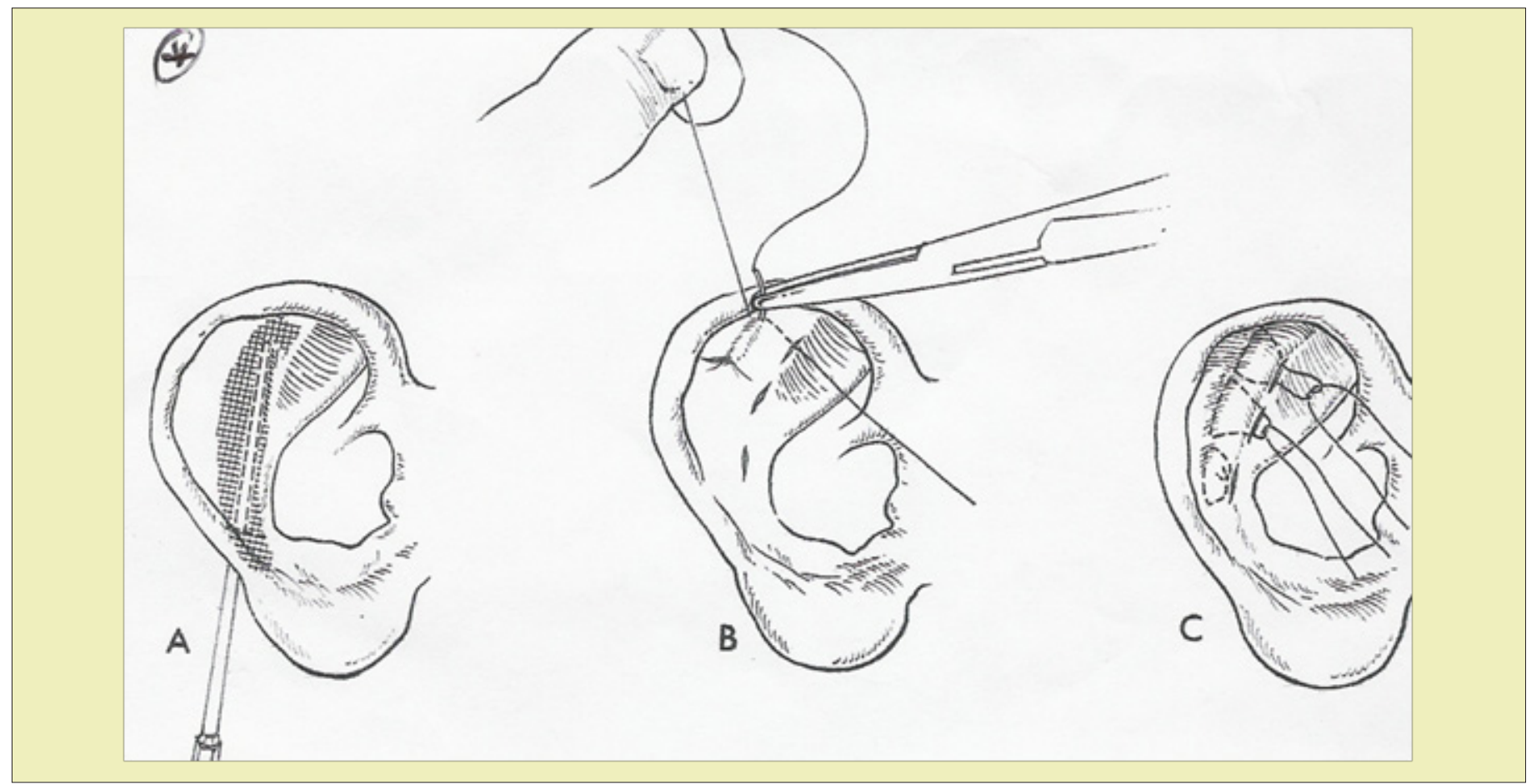




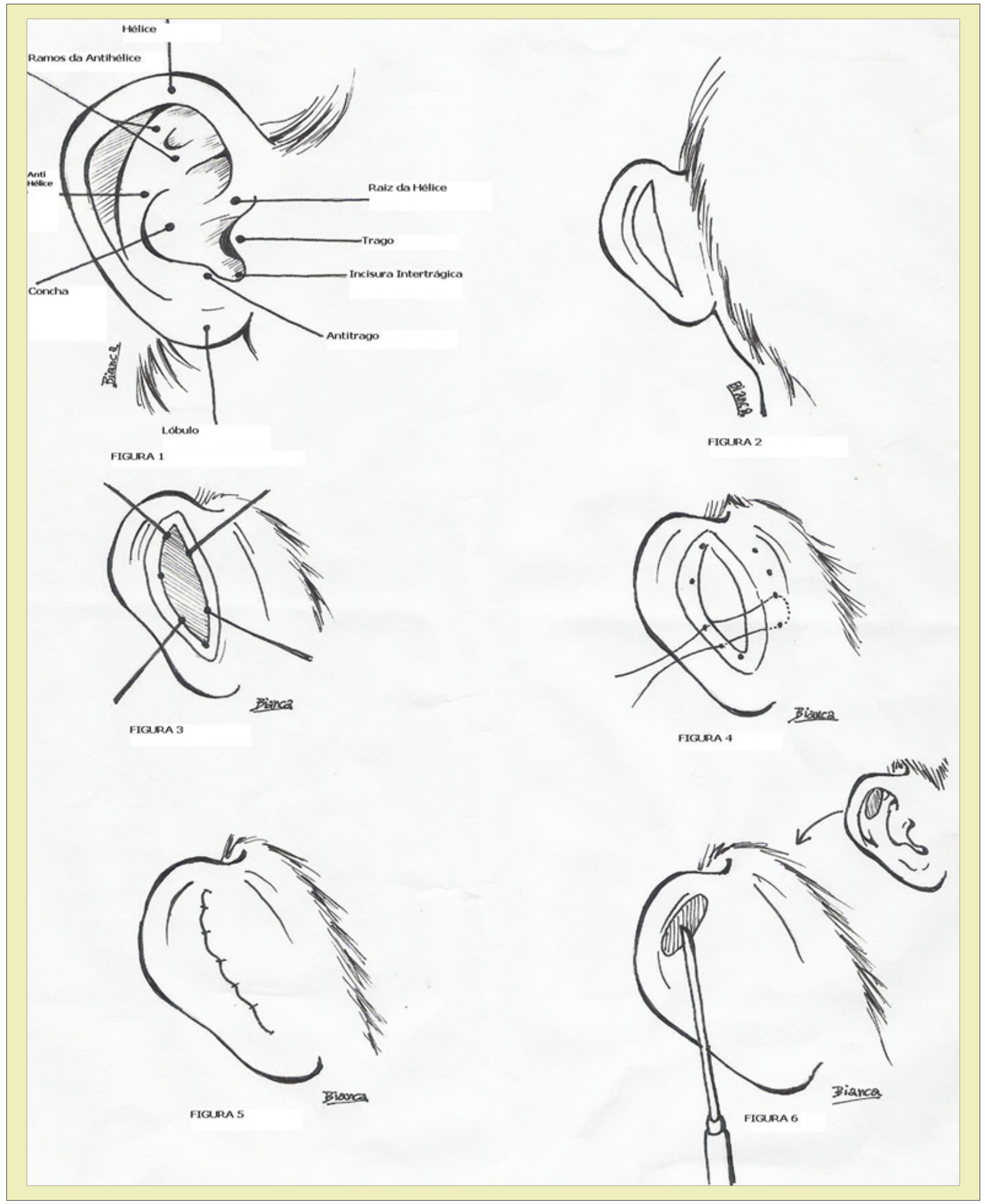



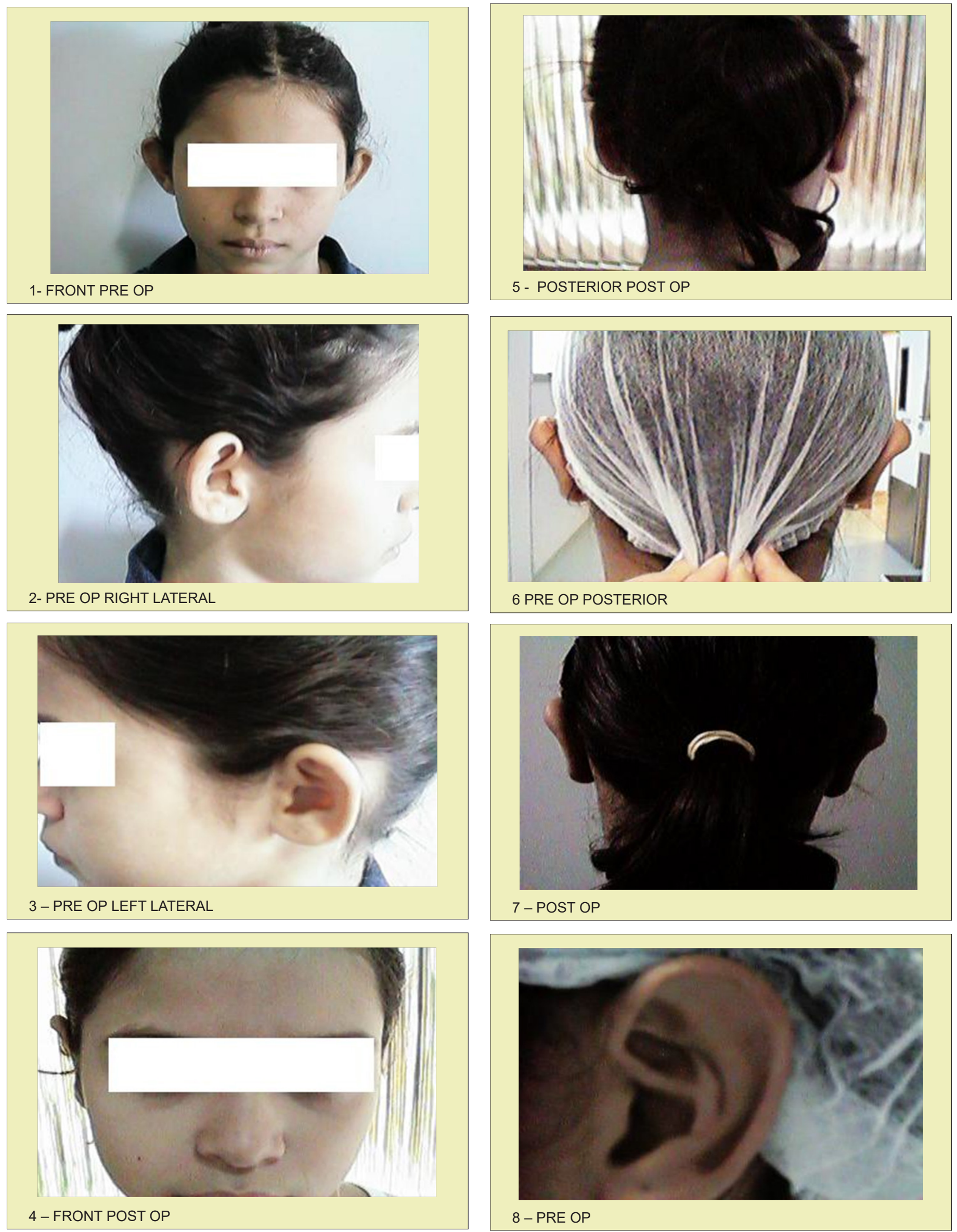

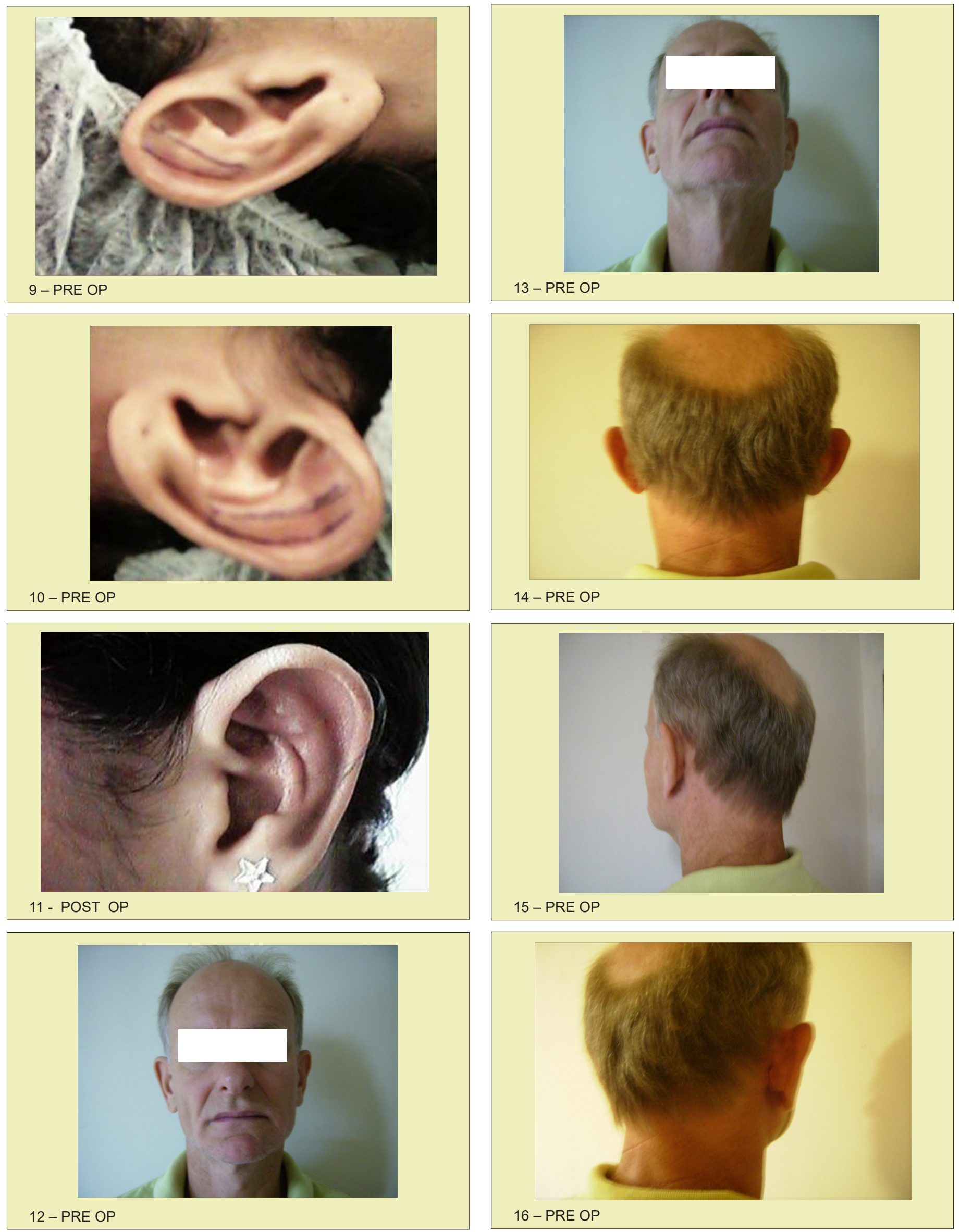

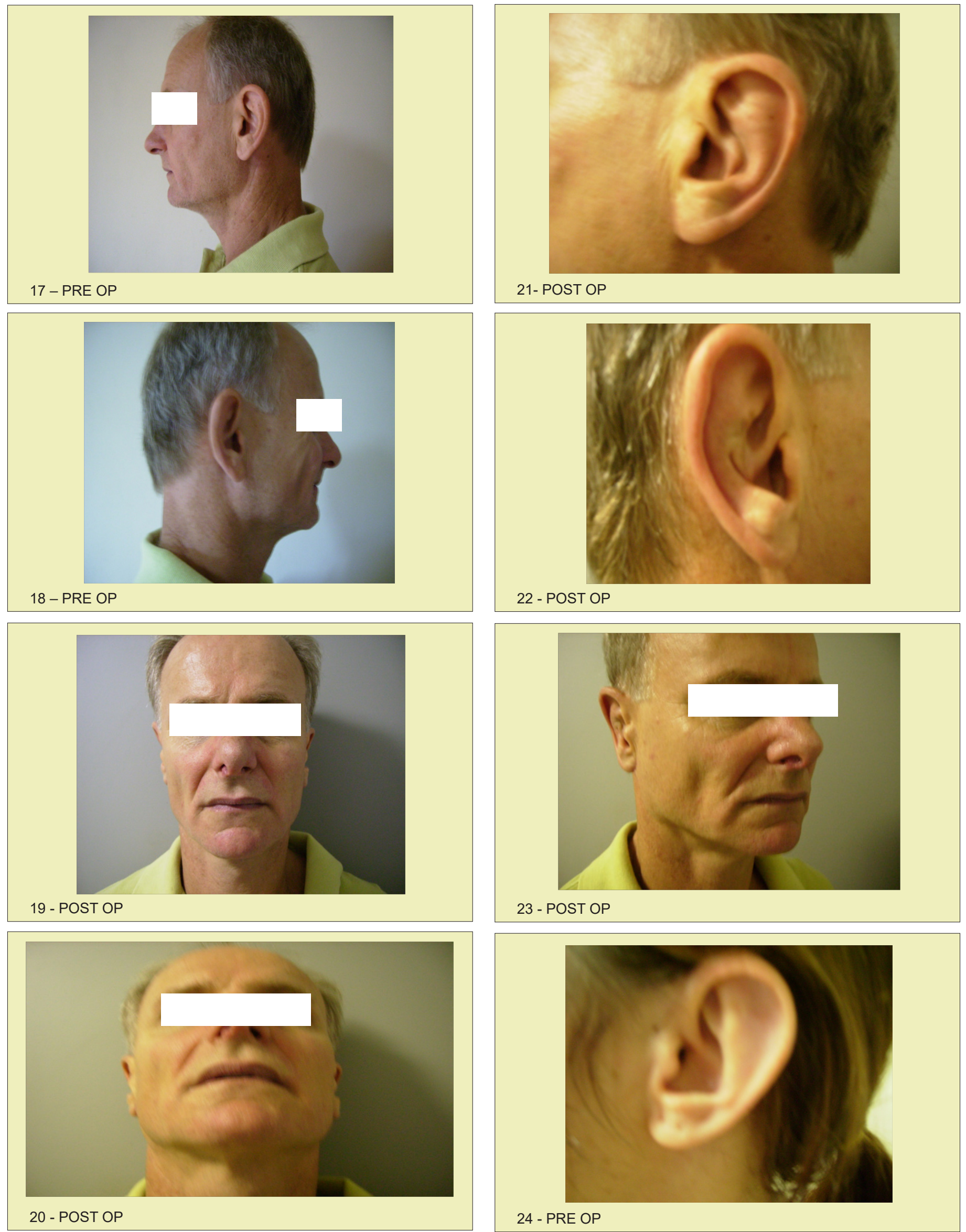

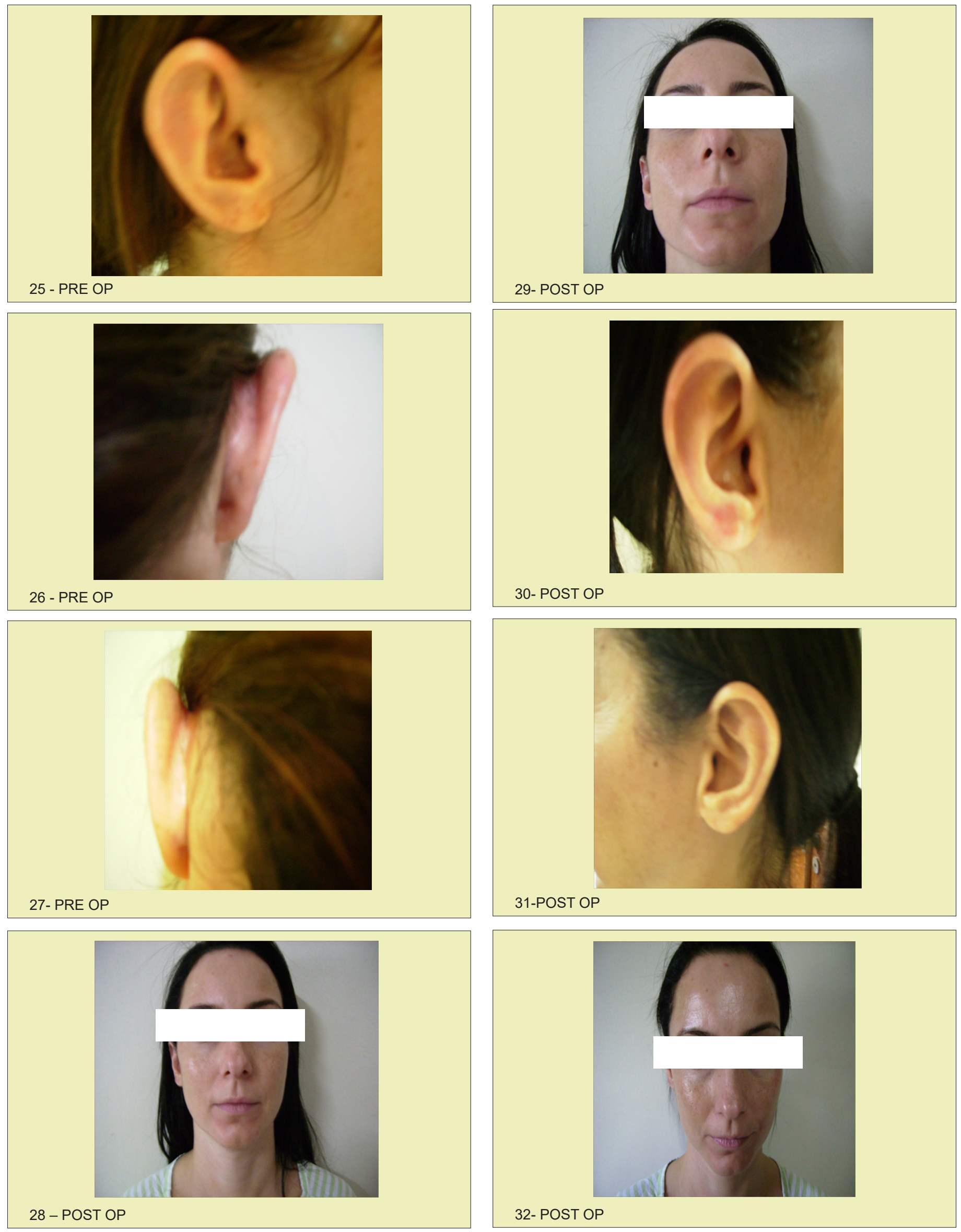

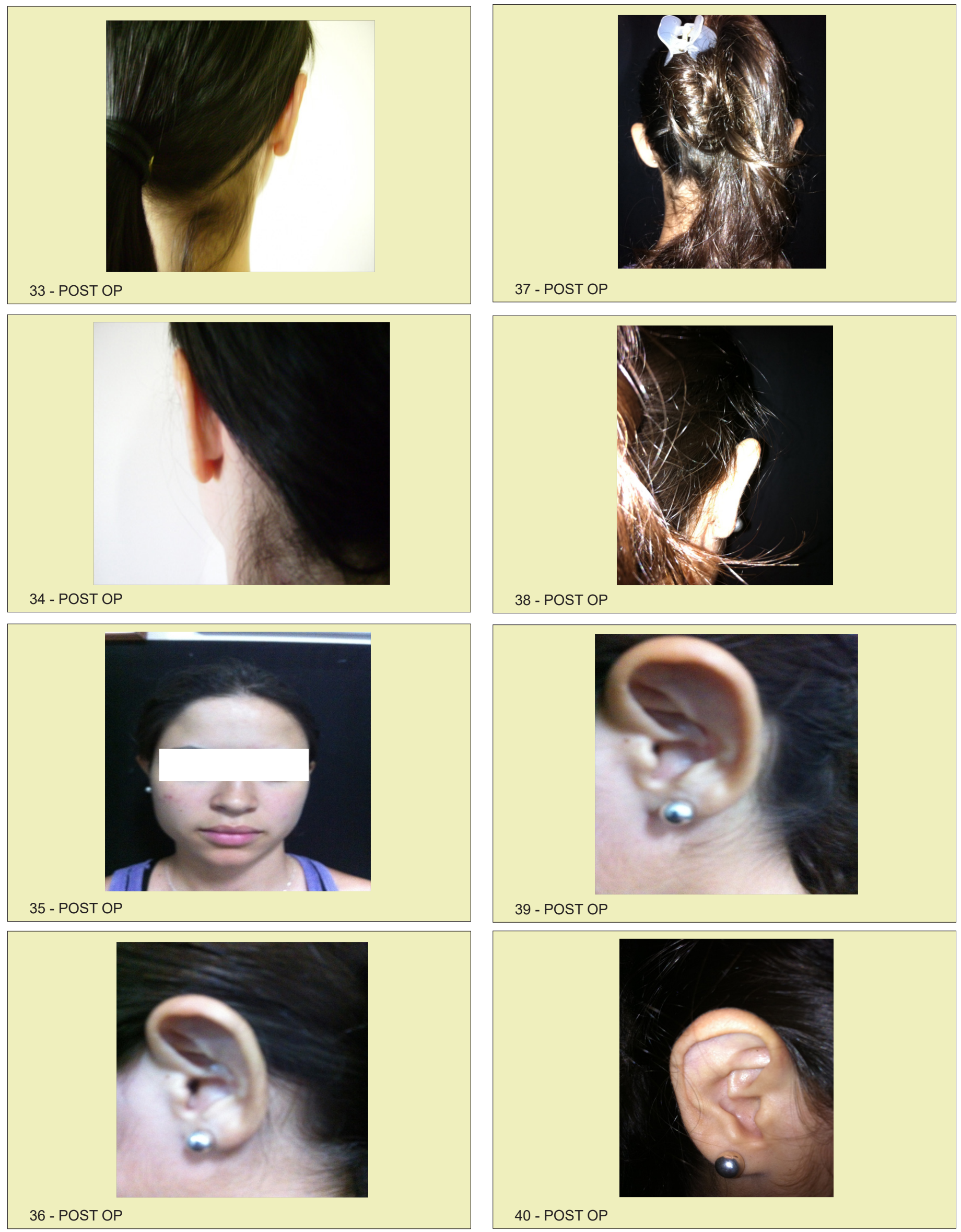